\title{
AVALIAÇÃO DA DESNITROGENAÇÃO EM FUNÇÃO DO TEMPO NO DESGASEFICADOR A VÁCUO DA USIMINAS*
}

\author{
Flavio Viana Diniz Soares ${ }^{1}$ \\ Marlon Jose dos Anjos Silva ${ }^{2}$ \\ Pedro Henrique Coelho Soares ${ }^{3}$ \\ Aline Lima da Silva ${ }^{4}$ \\ Luiz Fernando Andrade de Castro ${ }^{5}$
}

\section{Resumo}

Neste trabalho foi avaliada a desnitrogenação ao longo do tratamento no Desgaseificador a vácuo - $\mathrm{RH} 2$ da Usiminas, a partir da amostragem de 10 corridas de aço estrutural para chapa grossa de classe de resistência mecânica de $50 \mathrm{kgf} / \mathrm{mm}^{2}$ microligado com nióbio e titânio, de composição química e em condições de processo similares. Foram retiradas amostras de aço nos tempos 0, 5, 10, 15 e 20 minutos de cada corrida. Os dados foram tratados em dois grupos baseado no teor inicial de nitrogênio. Para o grupo de corridas com o teor menor que 39 ppm, não se verificou redução nos valores de nitrogênio após o tratamento no $\mathrm{RH}$. No grupo de corridas com teor de nitrogênio acima de 39 ppm, evidenciou-se uma redução média de $17 \%$ do teor de nitrogênio. Além disso, o teor médio final de nitrogênio em ambos os grupos ficaram com diferença de apenas 2 ppm, evidenciando que o desgaseificador a vácuo $\mathrm{RH}$ foi eficiente na redução de nitrogênio para teores acima de $39 \mathrm{ppm}$.

Palavras-chave: Desgaseificador RH; Desnitrogenação.

\section{DENITROGENATION EVALUATION AS A FUNCTION OF TIME IN USIMINAS RH2 DESGASSER}

\begin{abstract}
In this work, the denitrogenation was evaluated along the treatment in the Usiminas degasser - $\mathrm{RH} 2$, from the sampling of 10 steel heats for heavy plate of mechanical resistance $50 \mathrm{kgf} / \mathrm{mm}^{2}$ with niobium and titanium, of under similar chemical composition and process conditions. Steel samples were taken at 0, 5, 10, 15 and 20 minutes of each heat. The data were treated in two groups based on the initial nitrogen content. For the group of heats with nitrogen content less than $39 \mathrm{ppm}$, there was no reduction in nitrogen values after treatment in $\mathrm{RH}$. In the group of heats with nitrogen content above $39 \mathrm{ppm}$, was evidenced an average reduction of $17 \%$ of nitrogen content. In addition, the final nitrogen content in both groups was only $2 \mathrm{ppm}$ difference, evidencing that the $\mathrm{RH}$ Degasser was efficient in reducing nitrogen with content above 39 ppm.
\end{abstract}

Keywords: $\mathrm{RH}$ degasser; Denitrogenation.

1 Engenheiro Metalurgista, Mestrando em Engenharia Metalúrgica, Materiais e Minas do PPGEM UFMG, Belo Horizonte, MG, Brasil; Gerente Técnico de Aciaria, Usiminas; Ipatinga, MG, Brasil.

2 Engenheiro Metalurgista e Mestre em Engenharia Metalúrgica, Especialista da Gerência Técnica de Aciaria, Usiminas; Ipatinga, MG, Brasil.

3 Engenheiro de Materiais, Engenheiro Gerência Técnica de Aciaria, Usiminas; Ipatinga, MG, Brasil.

4 Engenheira Metalurgista; Professora Doutora do Departamento de Engenharia Metalúrgica da UFMG, Belo Horizonte, MG, Brasil.

5 Engenheiro Metalurgista; Professor Doutor do Departamento de Engenharia Metalúrgica da UFMG, Belo Horizonte, MG, Brasil. 


\section{INTRODUÇÃO}

O nitrogênio é um elemento indesejável quando se busca a redução de defeitos superficiais em placas. Quanto maior o teor de nitrogênio dos aços, maior a probabilidade de formação de nitretos de alumínio e consequentemente a geração de defeitos superficiais em placas de aços para chapas grossas.

Para produção dos aços chapas grossas na aciaria existem três etapas principais: refino primário, refino secundário e lingotamento. As etapas de refino são responsáveis pelo acerto de composição química, limpidez e ajuste de temperatura dos aços. No refino secundário da Usiminas os aços chapas grossas de elevado rigor são tratados no CAS-OB ou forno panela e posteriormente enviados ao desgaseificador a vácuo $\mathrm{RH}$ para redução do hidrogênio e nitrogênio.

Os teores de nitrogênio presentes no aço líquido dependem do tipo de tratamento realizado no refino primário e secundário, podendo variar de 15 até $100 \mathrm{ppm}$, conforme prática de cada usina. A principal fonte de nitrogênio para o aço líquido é o ar, ocorrendo o "pick-up" principalmente nos momentos de ressopro, vazamento, dessulfuração e homogeneização do aço. Pode ocorrer também o "pick-up" de nitrogênio durante o sopro de oxigênio quando do nitrogênio fora da especificação.

De acordo com Neves [1], a principal forma de redução do teor de nitrogênio se dá pela diminuição da pressão parcial do nitrogênio na câmara de vácuo e sucção deste para a chaminé através do sistema de vácuo. Considera-se que o nitrogênio dissolve-se nos metais na forma atômica e, desta maneira, a reação de remoção de nitrogênio pode ser expressa por:

$$
\begin{aligned}
& \underline{\mathrm{N}}=1 / 2 \mathrm{~N}_{2(\mathrm{~g})} ; \\
& K_{e q}=\left(P_{N_{2}}\right)^{2} / h_{N} \\
& \Delta \mathrm{G}^{\circ}(\mathrm{cal} / \mathrm{mol})=-860-5,71 . \mathrm{T}(\mathrm{K})
\end{aligned}
$$

Onde:

Keq = constante de equilíbrio da equação;

$\mathrm{P}_{\mathrm{N}_{2}}=$ pressão parcial do nitrogênio gasoso (atm);

$\mathrm{h}_{\mathrm{N}}=$ atividade henryana do nitrogênio no aço.

Estas relações indicam que o teor residual de nitrogênio pode ser reduzido através da devida redução parcial dos gases, limitado ao valor de equilíbrio das reações. Nos processos a vácuo, esta diminuição da pressão efetiva dos gases se dá pela utilização conjunta de vácuo e diluição via gás inerte, normalmente argônio.

$\mathrm{Na}$ figura 1, a redução da pressão tem efeito no aumento da área de interface gásmetal e maior agitação de banho expondo mais metal líquido a condições de vácuo, reduzindo o teor de nitrogênio, conforme relatado por Sau [2].

Aplicando as equações (2) e (3), a $1600^{\circ} \mathrm{C}$ e $0,001 \mathrm{~atm}$ de pressão, o teor de nitrogênio no equilíbrio é 14 ppm, valor que não é atingido em operação regular do refino do aço no $\mathrm{RH}$ devido ao controle cinético e composição química do aço. 


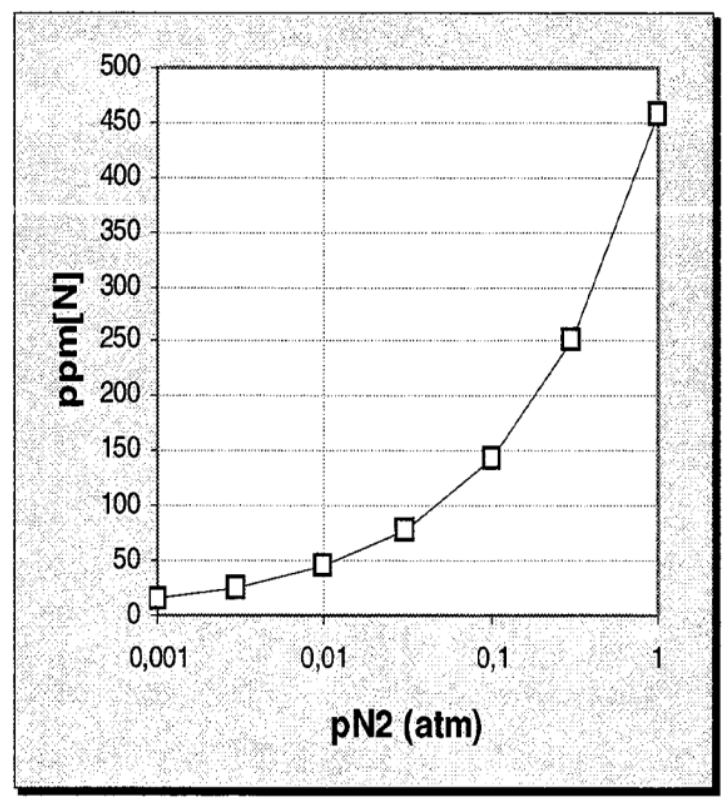

Figura 1. Solubilidade de equilíbrio do nitrogênio no ferro líquido a $1600^{\circ} \mathrm{C}$ (Fonte: Silva [3]).

Um fator importante a ser considerado é a influência de substâncias tensoativas na taxa de remoção de nitrogênio. A cinética da remoção do nitrogênio é prejudicada pela presença de elementos tensoativos como o enxofre e o oxigênio. Esses elementos bloqueiam os sítios de nucleação na interface metal-gás, de acordo com Silva [3]. A Figura 2 mostra a curva de remoção do nitrogênio para um $\mathrm{RH}$ de $85 \mathrm{t}$ em função do tempo de tratamento e do teor de enxofre contido no aço, conforme Sau [2]. Para diferentes concentrações de enxofre no aço, pode-se observar que a remoção de nitrogênio é mais eficiente para teores menores de enxofre. Verifica-se também uma estabilização dos teores para tempos de tratamento superiores a 40 minutos.

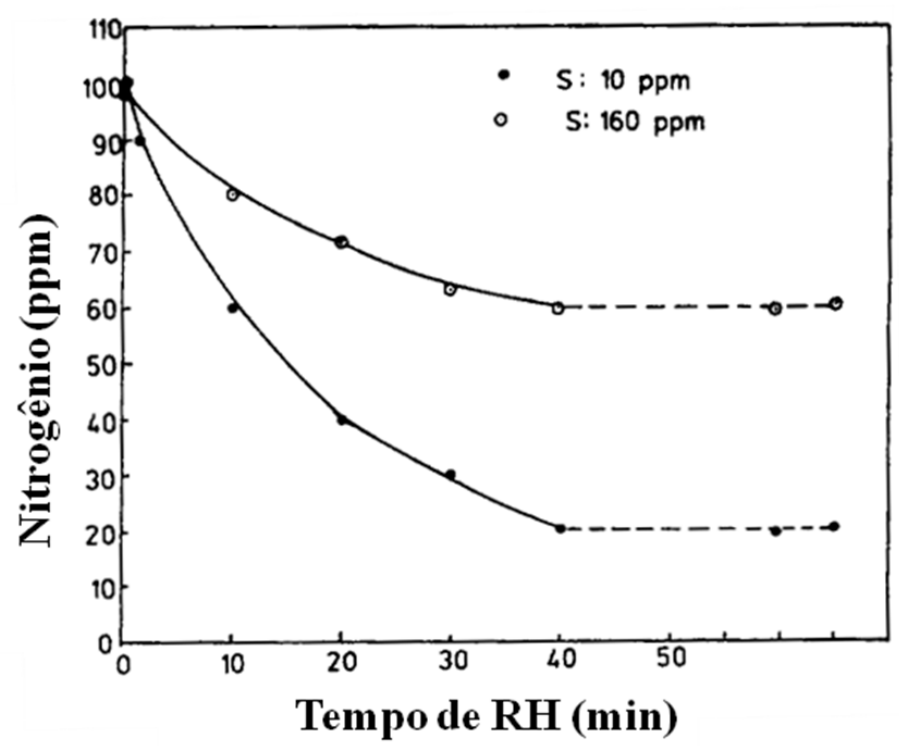

Figura 2. Curva de remoção do nitrogênio em função do tempo de tratamento no $\mathrm{RH}$ para diferentes teores de enxofre no aço (Fonte: Sau [2]). 
Um modelo foi proposto por Zhou [4] para descrever a remoção de nitrogênio durante a desgaseificação sob vácuo. Assim, conforme a Figura 3, temos as seguintes fases:

1 - Transferência de massa do [N] do banho para camada limite do líquido;

2 - Difusão do [N] na camada limite até a interface de reação;

3 - Reação química na interface líquido/gás;

4 - Difusão do $\mathrm{N}_{2}$ da interface de reação até a camada limite do gás;

5 - Transferência de massa do $\mathrm{N}_{2}$ da camada limite do gás até fase gasosa.

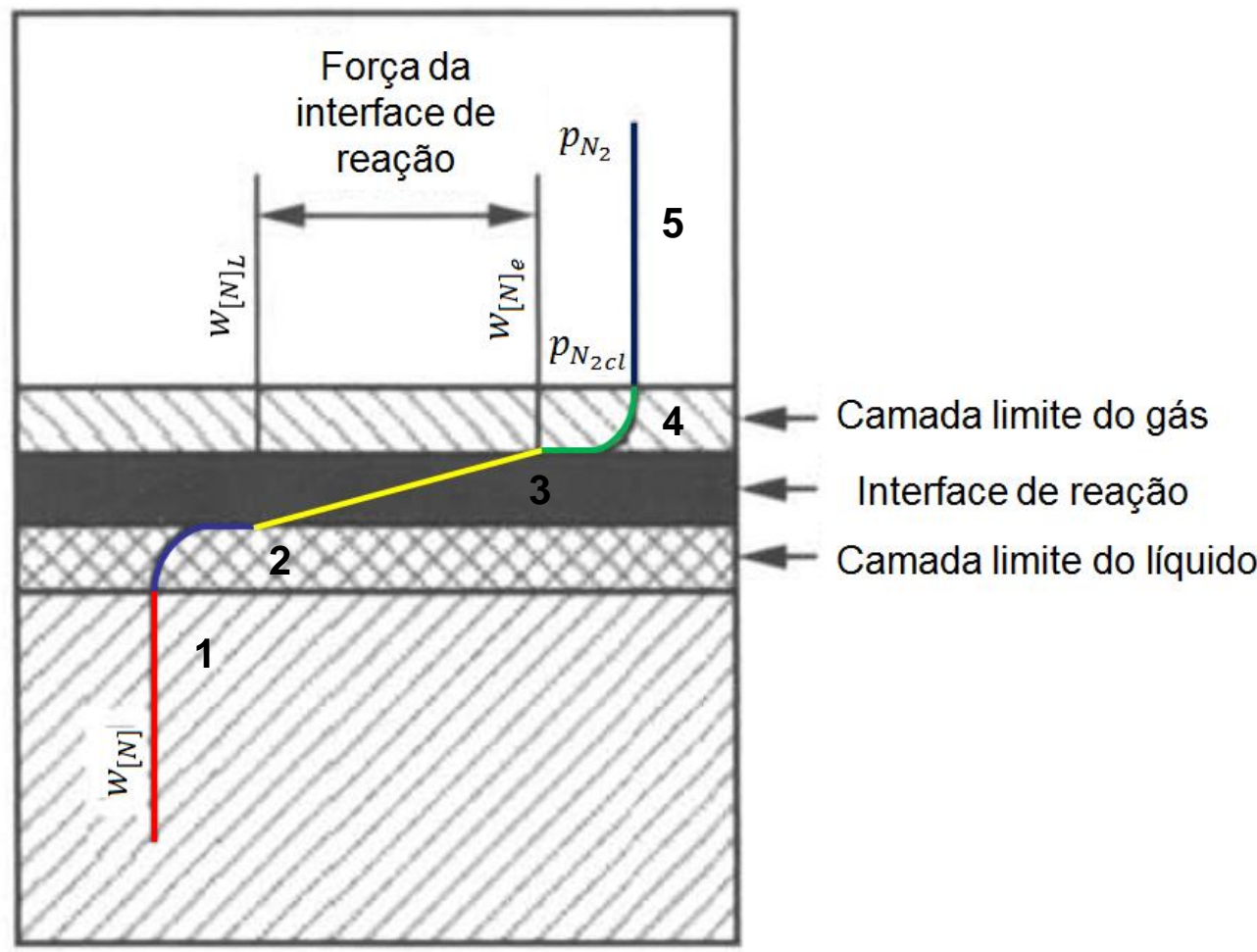

Figura 3. Esquema de modelo para remoção de nitrogênio (Fonte: Zhou [4]).

Tendo em vista a importância do conhecimento do comportamento do nitrogênio no aço líquido, este estudo teve como objetivo investigar a desnitrogenização no desgaseificador a vácuo ao longo do tratamento de um aço com baixo teores de tensoativos. 


\section{MATERIAIS E MÉTODOS}

\subsection{Desgaseificador a vácuo - RH2 da Usiminas}

$\mathrm{O}$ equipamento utilizado para realizar os testes foi o $\mathrm{RH} 2$ da Usiminas. As principais características do equipamento utilizado são mostradas na Tabela 1.

Tabela 1. Características principais do desgaseificador a vácuo $\mathrm{RH} 2$ da Usiminas - Ipatinga.

\begin{tabular}{lc}
\hline Capacidade nominal (toneladas/ano) & 1.200 .000 \\
\hline Peso da corrida (toneladas) & 170 \\
\hline Diâmetro do vaso $(\mathrm{mm})$ & 2070 \\
\hline Diâmetro interno da perna $(\mathrm{mm})$ & 600 \\
\hline Lança de injeção de oxigênio & T-COB \\
\hline Vazão de oxigênio $\left(\mathrm{Nm}^{3} / \mathrm{h}\right)$ & 2000 \\
\hline Vazão de argônio $\left(\mathrm{Nm}^{3} / \mathrm{h}\right)$ & 80 a 140 \\
\hline Número de bicos de injeção de argônio $(1$ nível) & 10 \\
\hline Taxa de circulação aproximada (toneladas/minuto) & 130 \\
\hline Troca rápida do vaso & Sim \\
\hline Capacidade de sucção a 0,5 torr $(\mathrm{kg} / \mathrm{h})$ & 650 \\
\hline Sistema de pré vácuo & Sim \\
\hline Aquecimento do vaso com lança & Sim \\
\hline Equipamento de amostragem & Automático \\
\hline Tempo de tratamento do aço chapa grossa (minutos) & 8 a 20 \\
\hline
\end{tabular}

\subsection{Processo de Amostragem}

Realizou-se o tratamento de 10 corridas de aço destinado a produto chapa grossa de classe de resistência mecânica de $50 \mathrm{kgf} / \mathrm{mm}^{2}$ microligado com nióbio e titânio e com tempo de tratamento de 20 minutos.

A composição típica do aço amostrado ao final do tratamento no $\mathrm{RH}$ está listada na tabela 2. Este aço foi escolhido por ter baixo teor dos elementos tensoativos, oxigênio e enxofre, minimizando a influência desses na análise dos dados.

Tabela 2. Composição Típica do aço amostrado no final do tratamento no RH.

\begin{tabular}{c|c|c|c|c|c|c|c|c|c}
\hline $\mathbf{C}$ & $\mathbf{M n}$ & $\mathbf{S i}$ & $\mathbf{P}$ & $\mathbf{A l}$ & $\mathbf{S}$ & $\mathbf{N b}$ & $\mathbf{T i}$ & $\mathbf{O}$ & $\mathbf{N}$ \\
\hline $0,16 \%$ & $1,38 \%$ & $0,21 \%$ & $0,019 \%$ & $0,031 \%$ & $0,004 \%$ & $0,034 \%$ & $0,020 \%$ & $<30 \mathrm{ppm}$ & $0,0035 \%$ \\
\hline
\end{tabular}

Retiraram-se cinco amostras de cada corrida, nos seguintes momentos:

- Primeira amostra - antes do tratamento no RH (amostra A0),

- Segunda amostra - 5 minutos de tratamento no RH (amostra $A_{5}$ ),

- Terceira amostra - 10 minutos de tratamento no $\mathrm{RH}$ (amostra $\mathrm{A}_{10}$ ),

- Quarta amostra - 15 minutos de tratamento no RH (amostra $A_{15}$ )

- Quinta amostra - 20 minutos de tratamento no $\mathrm{RH}$ (amostra $\mathrm{A}_{20}$ ).

O equipamento de amostragem no $\mathrm{RH}$ pode ser visto na Figura 4. 


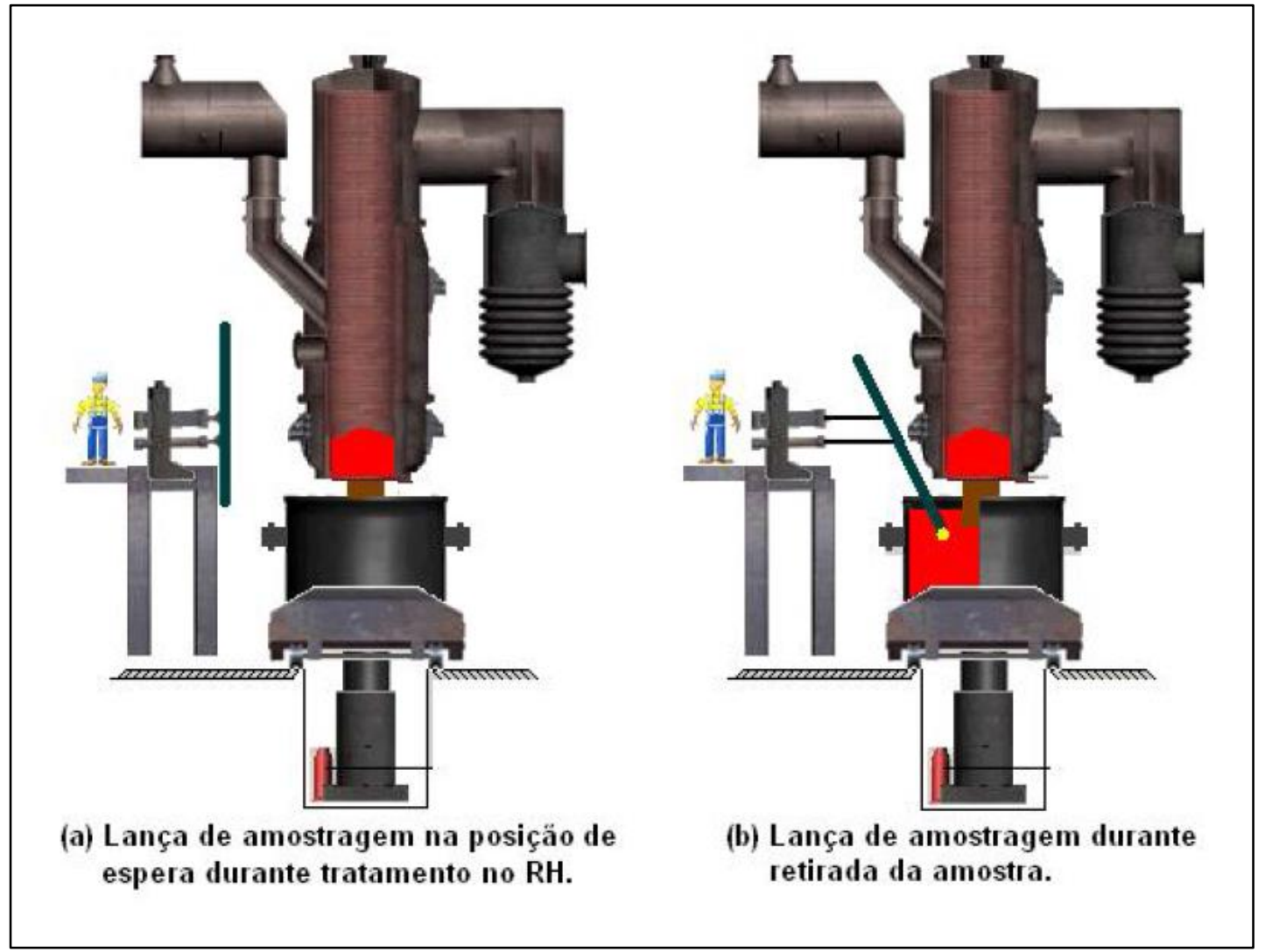

Figura 4. Lança de amostragem automática no RH. (Fonte: Silva [5]).

\subsection{Amostra}

Para a retirada da amostra foi utilizado um amostrador tipo "pirulito", com revestimentos especiais para prevenção de contaminação.

\subsection{Análise de nitrogênio}

A análise de nitrogênio das amostras foi realizada em equipamento LECO TC-436 por diferença de termocondutividade.

\section{RESULTADOS E DISCUSSÃO}

\subsection{Análise da curva de desnitrogenação}

A distribuição do nitrogênio ao longo do tratamento no $\mathrm{RH}$ de todas as corridas é apresentada na Figura 5. Observamos que o nitrogênio médio inicial (A0) foi de 38 ppm e após 20 minutos (A20) de tratamento foi reduzido a 35 ppm. Assim, ocorreu uma redução de apenas $8 \%$ do teor de nitrogênio médio das corridas.

Posteriormente, separaram-se os dados em dois grupos. No primeiro grupo, tem-se teores iniciais de nitrogênio maior ou igual a 39 ppm. Já no segundo grupo, tem-se teores iniciais menores que $39 \mathrm{ppm}$. 


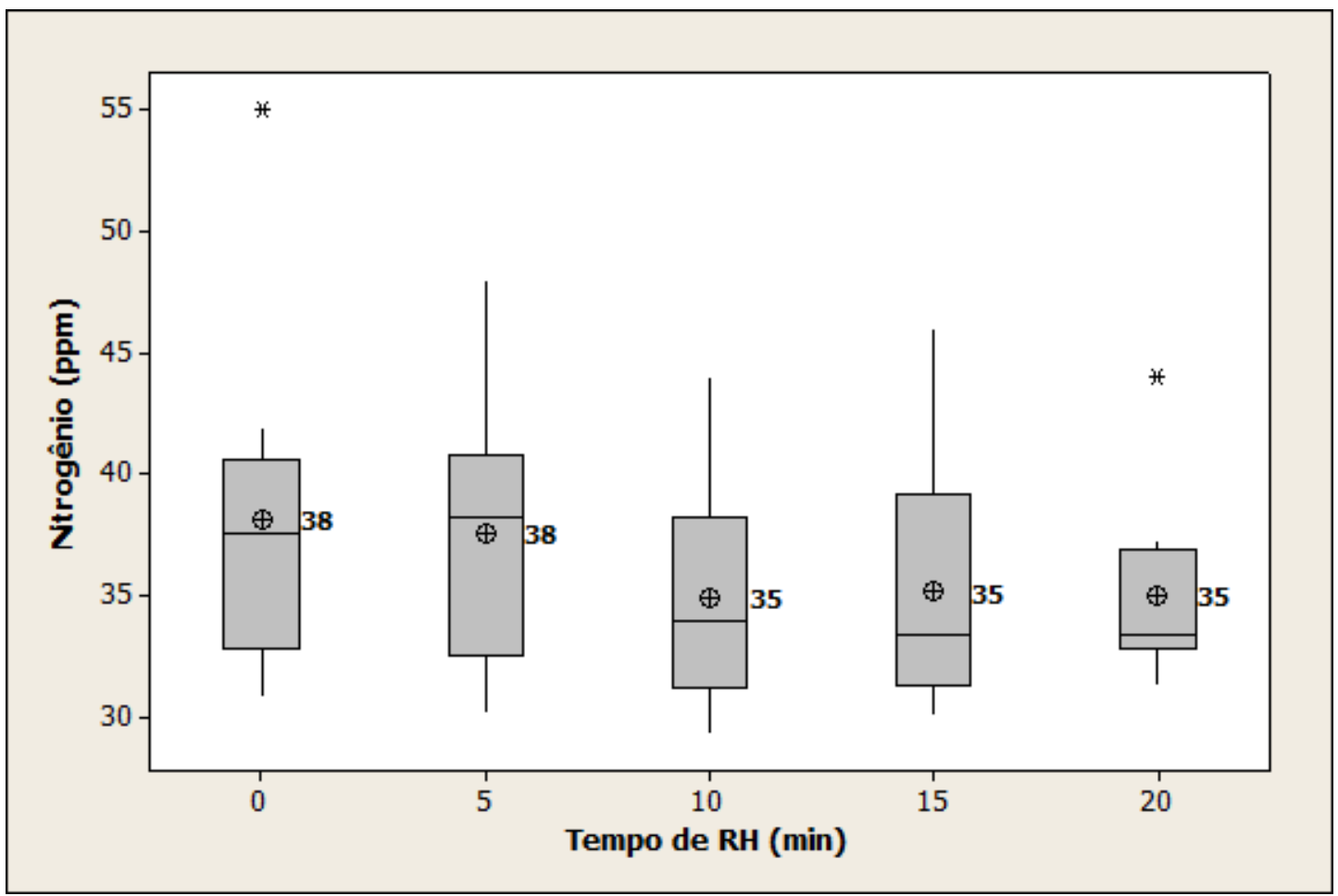

Figura 5. Teor de nitrogênio obtido ao longo do tempo de todas as corridas analisadas.

Observa-se na Figura 6 que corridas com teores iniciais de nitrogênio igual ou acima de $39 \mathrm{ppm}$ apresentaram maior redução do teor de nitrogênio. O nitrogênio médio inicial para este primeiro grupo foi de $44 \mathrm{ppm}$ e o final de $36 \mathrm{ppm}$, com uma redução média de 17\%. Observa-se, também, que não ocorreu desnitrogenação após os 15 minutos de tratamento, mostrando que o processo chegou próximo ao equilíbrio nas condições analisadas.

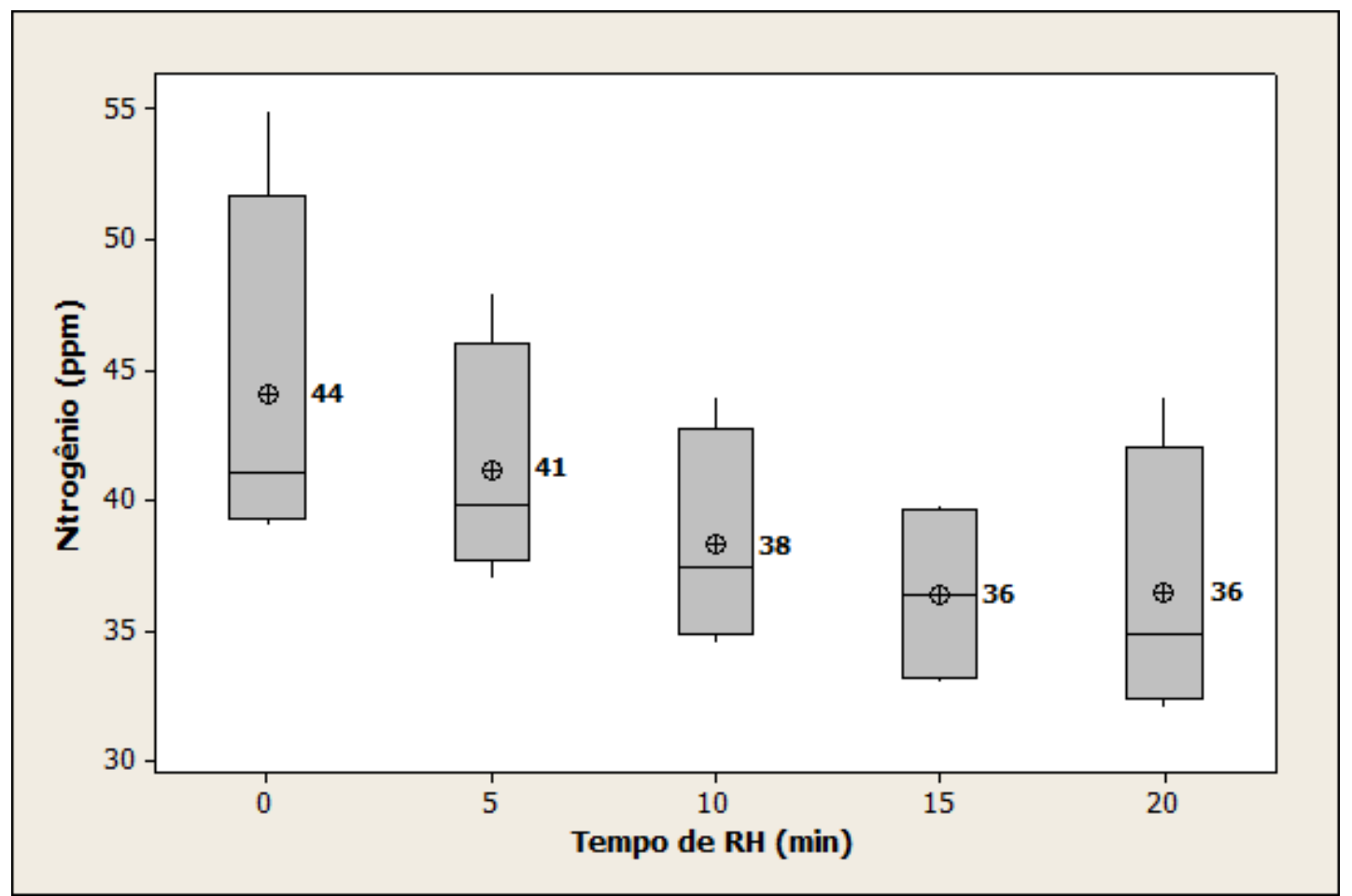

Figura 6. Teor de nitrogênio obtido ao longo do tempo para corridas com nitrogênio inicial maior ou igual a $39 \mathrm{ppm}$. 
Para as corridas do segundo grupo, com nitrogênio inicial abaixo de 39 ppm, não se verifica redução do teor durante o tratamento no $\mathrm{RH}$, como pode ser visto na Figura 7.

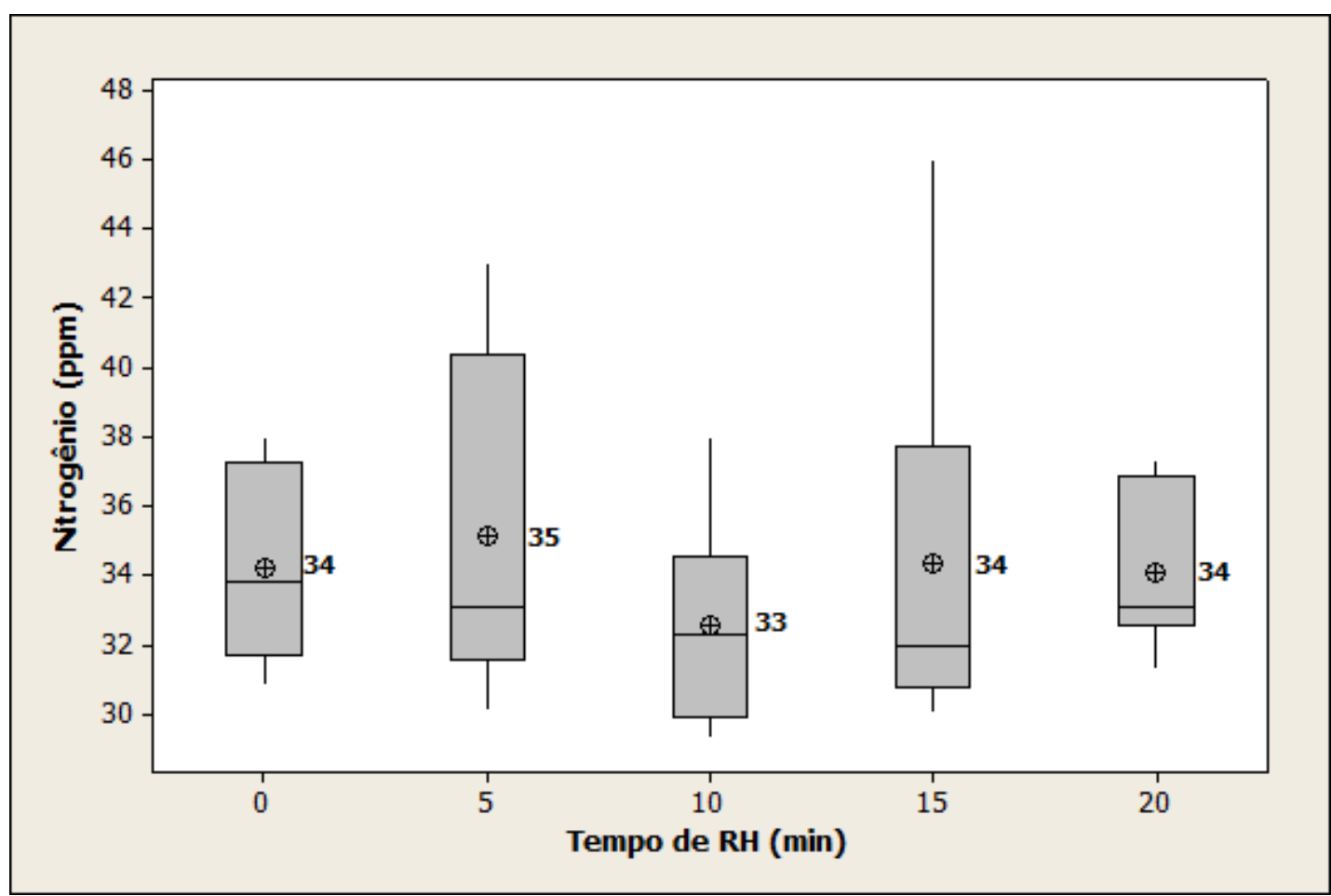

Figura 7. Teor de nitrogênio obtido ao longo do tempo para corridas com nitrogênio inicial menor que $39 \mathrm{ppm}$.

A elevação do nitrogênio, observada para os tempos de 5 e 15 minutos, deve-se à realização de adições de ligas e refrigerantes que contém nitrogênio residual em sua composição e, consequentemente, interferem nesse resultado.

Independente do teor inicial do nitrogênio, os valores finais de nitrogênio em ambos os grupos analisados ficaram próximos, com uma variação de $2 \mathrm{ppm}$. Isto evidencia a efetividade do $\mathrm{RH}$ para reduzir nitrogênios elevados, mas que não se torna significativo quando o nitrogênio já está próximo ao equilíbrio.

\section{CONCLUSÃo}

Foi constatado que o teor de nitrogênio inicial influencia a desnitrogenação.

No grupo de aços com teor de nitrogênio menor que 39 ppm, foi observado que não ocorreu a desnitrogenação.

No grupo dos aços com teor de nitrogênio igual ou acima de 39 ppm, verificou-se uma desnitrogenação de 17\%.O teor médio final de nitrogênio em ambos os grupos ficaram com diferença de apenas 2 ppm, evidenciando que o desgaseificador a vácuo $\mathrm{RH}$ foi eficiente na redução de nitrogênio para teores acima de 39 ppm.

Além disso, após 15 minutos de tratamento, não ocorreu redução do nitrogênio, evidenciando estar próximo ao equilíbrio para as condições de processo analisadas. 


\section{REFERÊNCIAS}

1 NEVES; L. Avaliação dos efeitos da injeção de gás na câmara de vácuo do modelo físico de um desgaseificador $\mathrm{RH}$. Dissertação de Mestrado em metalurgia extrativa; Escola de Engenharia; Universidade Federal de Minas Gerais; Belo Horizonte; 2008.

2 SAU, R.; RAY, A.K.; JAGANNATHAN, K.P. Nitrogen removal in steel - critical issues. In: Transactions of the Indian Institute of Metals (India). Vol. 52, n 1, fev. 1999, p. 5561.

3 SILVA et al. 2005. Curso de Refino Secundário dos Aços, ASSOCIAÇÃO BRASILEIRA DE METALURGIA E MATERIAIS, ABM, Belo Horizonte, p. 490, 03 a 07 out. 2005.

4 ZHOU, J. et al. Behaviors of Denitrogenation in RH-MFB. In: Journal of Iron and Steel Research, International. v.20, n.7, p.40-44. 2013.

5 SILVA; M. J. A. Variação da taxa de descarburação para vários padrões de injeção de argônio na perna de subida do desgaseificador a vácuo $\mathrm{RH}$. Dissertação de Mestrado em metalurgia extrativa; Escola de Engenharia; Universidade Federal de Minas Gerais; Belo Horizonte; 2010.

6 KLEIMT et al. Secondary steelmaking - Improvement of vacuum circulation plant operation on the basis of the BFI simulation model; Luxembourg; European Commission, 2001, p. 175.

7 CASTRO, L. F. A.; SAMPAIO, R. S.; TAVARES, R. P.; Termodinâmica Metalúrgica. Texto Preparado pelos Professores. Capítulo 2, Primeira Lei da Termodinâmica, p. 94.

8 CARVALHO, J. L. R., CAMILO, R. D., FIGUEIRA, R. M., CAMPOS, V. C., Dados termodinâmicos para metalurgistas, Escola de Engenharia da Universidade Federal de Minas Gerais, Belo Horizonte, MG, Fevereiro, 1977.

9 KLEIMT, B.; et al. Dynamic model for on-line observation of the current process state during $\mathrm{RH}$ degassing. In: Steel Research, v.72, n.9, p.337-345, set. 2001.

10 MINTZ, B. Influente of nitrogen on hot ductility of steels and its relationship to problem of transverse cracking, In: Ironmaking and Steelmaking, v.27, n.5, p.343-347. 2000. 